\title{
Analysis of the highway tunnels monitoring using an optical fiber implemented into primary lining
}

\author{
Marcel Fajkus*, Jan Nedoma*, Pavel Mec ${ }^{* *}$, Eva Hrubesova $^{* * *}$, \\ Radek Martinek $^{* * * *}$, Vladimir Vasinek ${ }^{*}$
}

\begin{abstract}
This article is focused on the analysis of the use of distributed fibre-optic technology for security monitoring of road tunnel and motorway tunnel structural load. The authors focused on the measurements of deformation utilizing Brillouin Time Domain Reflectometry (BOTDR). The principle is based on the measurement of stimulated Brillouin scattering. The article describes and analyses real measurements within a period of 5 months, which were carried out during the tunnelling and the whole process of building a new tunnel in Žilina, Slovakia. The performed experimental measurements were carried out using a standard optic telecommunication cable with water-absorbing aramid yarns and a jacket with a diameter of $4.2 \mathrm{~mm}$. The contribution of this article lies in the introductory analysis of the implementation and use of the fibre-optic technology for security monitoring of road tunnel and motorway tunnel structural load.
\end{abstract}

K e y w o r d s: Brillouin time domain reflectometry (BOTDR), fibre-optic sensor

\section{Introduction}

The construction of tunnels is closely related to ground movement monitoring. Currently, standard geodetic methods, stringed and piezoelectric sensors are used for geotechnical monitoring [1-6]. Monitoring of underground workings can be basically divided into underground monitoring on the site of construction and surface monitoring. The objectives of the monitoring are based on the basic hypotheses for system transformation of "rock environment - the support of the underground workings" $[7,8]$. By building the underground workings, the primary balance is broken leading to the redistribution of stress, and the concentration of stress behind the excavation reaches a value that is several times higher than the primary stress. The change in the stress take place simultaneously with deformation signs, there are radial movements into the centre of the construction, an extrusion may also occur (the face bulge to the excavation). Behind the contour of the workings, an area of plastic deformation occurs, causing increased pressure on the support of the workings. The construction of the underground workings, especially in the case of shallow tunnelling, has negative effects on the surface too - settlement troughs emerge and their extent and nature influence the degree of negative effects of tunnelling on the surface (settlement, holes in objects, disruptions to the system of ground water, etc) [9-12]. The main objective of the monitoring lies in the verification of the project assumptions; the application of the observational method of the tunnel con- struction when the project is modified on the basis of the evaluation of geotechnical monitoring measurements, and also in ensuring safety during the construction process and minimizing the negative effects of the construction. Geotechnical monitoring therefore must be an integral part of all tunnelling methods, and its core objective is to achieve an optimum synergy of the rock mass and the support. Theoretically, these parameters of this optimum synergy of the rock mass with the tunnel support are given by an operating spot defined from Fenner-Pacher curve (the operation deformation features of rock mass and the support). The optimum value of the part of radial deformation of the rock mass, which takes place before the installation of the support itself, can significantly lower the load that is applied to the support. When the installation of the support takes too long, a rapid deformation of the excavation can take place, which can lead to the collapse of the whole stope [13-17]. One of the possible ways of extending the classic method of monitoring the load of tunnels is with optical fibres.

With the development of optical fibres, current conventional sensors are slowly being replaced by fibre-optic sensors. In the current installation, fibre Bragg grating sensors (FBG) or distributed sensors based on Brillouin scattering (BOTDR) are increasingly utilized for building construction monitoring [18]. Fibre Bragg gratings are implemented together with anchoring bars that serve for the reinforcement of rock bodies. This approach is used to monitor the stress and deformation levels in the anchors, and it enables warning of rock mass movement and its

* Department of Telecommunications, Faculty of Electrical Engineering and Computer Science, ** Department of Building Materials and Diagnostics of Structures, Faculty of Civil Engineering, *** Department of Geotechnics and Underground Engineering, Faculty of Civil Engineering, **** Department of Cybernetics and Biomedical Engineering, Faculty of Electrical Engineering and Computer Science, VSB - Technical University of Ostrava,17. listopadu 15/2172, 70833 Ostrava, Czech Republic,\{marcel.fajkus, jan.nedoma, pavel.mec, eva.hrubesova, radek.martinek, vladimir.vasinek\}@vsb.cz 
failures [19-23]. FBG are also used for the measurement of deformation in the secondary lining of tunnels [24-27] where quasi-distributed measurement with the help of multiplex techniques can be used [28,29]. The systems based on Brillouin scattering are beneficial with regard to the distribution of deformations along the whole optical fibre. Special optical cables with close binding of the optical fibre to the cover materials of the optical fibre are used for such purposes. Recent studies show that standard optical fibres can also be used for specific applications [30-32]. In tunnelling, BOTDR distributed systems are most often used for the measurement of tunnel lining deformation. For this use, the opening of the joints between individual segments of tunnel lining is examined the most during the excavation of tunnels [33-35]. Moreover, these systems are used for the monitoring of sprayed concrete lining and rock movements [36-40]. The advantage of the system based on Brillouin scattering is that it can cover an area of measurement that is several times larger because the used fibre serves as a sensor, on the contrary to the system with FBG sensors.

\section{Methods}

\subsection{Brillouin Optical Time Domain Reflectometer}

This method (BOTDR) is an optical method for distributed monitoring of deformation and temperature along the optical fibre. Distributed temperature and strain system (DSTS) is a device that allows the analysis of temperature or deformation effects on optical fibres with a spatial resolution of $1 \mathrm{~m}$. The general principle of measurement with this system is based on the phenomenon called stimulated Brillouin scattering. Stimulated Brillouin scattering in the optical fibre is a nonlinear phenomenon caused by the interaction of monochromatic light (pump signal) and acoustic waves. The acoustic field in the optical fibre can arise by the spontaneous thermal motion of particles in the optical fibre. This acoustic field propagates with the speed of sound $v_{A}$ defined by

$$
v_{A}=\sqrt{\frac{K}{\rho^{\prime}}}
$$

where $K$ is the bulk modulus of compressibility and $\rho$ is the density of the material determined by the magnitude of temperature and strain acting on the used optical fiber. This propagated acoustic field periodically modulates the refractive index of the fibre.

The light passing through the fibre is scattered, and the scattering light has a frequency shift compared with the incident light, which is the called Brillouin frequency shift $v_{B}$. The Brillouin scattering produces components called Stokes and Anti-Stokes components (Fig. 1). Maximal stimulated Brillouin scattering is then achieved when the frequency of the Stokes signal and the frequency of the pump signal are accurately separated by size of Brillouin shift. Standard telecommunications optical fibre
$\left(\mathrm{SiO}_{2}\right)$ have an ordinary shift of the Brillouin frequency of $10.83 \pm 0.015 \mathrm{GHz}$, and this change corresponds to a change of $0.1 \mathrm{~nm}$ at a wavelength of $1550 \mathrm{~nm}$.

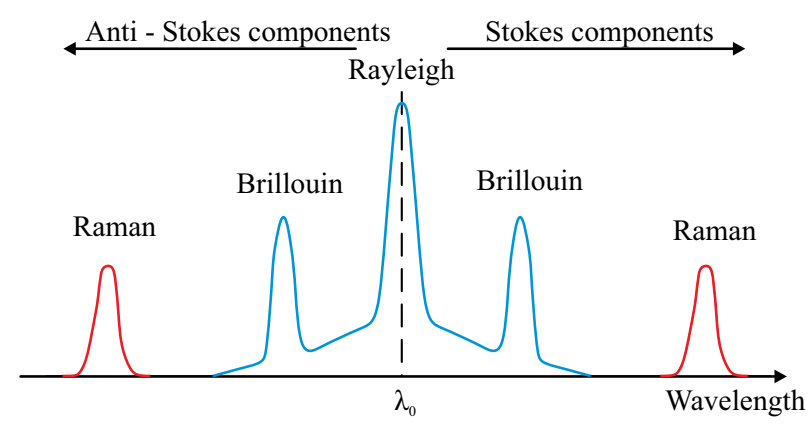

Fig. 1. Rayleigh, Brillouin and Raman scattering in the optical fiber

The Brillouin frequency shift is linearly dependent on the temperature and deformation by the equation

$$
v_{B}(T, \varepsilon)=v\left(T_{0}, 0\right)+C_{\varepsilon} \varepsilon+C_{T}\left(T-T_{0}\right)
$$

where $v_{B}(T, \varepsilon)$ represents the Brillouin frequency shift at a temperature $T$ with an axis strain $\varepsilon, v(T, 0)$ represents the Brillouin frequency shift at the temperature $T_{0}$ without axis strain, and $C_{\varepsilon}$ and $C_{T}$ are the coefficients of temperature and axis strain, respectively. For standard single mode optical fibers, $\varepsilon$ is $0.5 \mathrm{GHz} / \%$ and $C_{T}=1.3 \mathrm{MHz} /{ }^{\circ} \mathrm{C}[41,42]$.

\section{Experimental setup}

\subsection{Description of the highway tunnel}

The practical part of this article focuses on the analysis of highway tunnel monitoring using an optical fibre implemented into the primary lining. The implementation of the optical cable was performed during the excavation of the new one-way highway tunnel in Žilina (Slovakia) that is $867 \mathrm{~m}$ long. Above the tunnel is unstable agricultural land, forests and meadows, with an overburden height ranging from 5 to $40 \mathrm{~m}$. Significantly disturbed rock mass that is mainly composed of claystone and clayey soil indicates issues related to the progress of the excavation. The intervention in the stressed condition of the degraded rock mass leads to a large increase in deformation that causes the creation of eased areas around the stope or the face of the tunnel. Due to an unstable overburden of the tunnel, the primary requirement of the company Metrostav, which carried out the construction, was to monitor the development of the change of the load over time. The tunnel is excavated using the New Austrian Tunnelling Method (NATM), also known as the sequential excavation method (SEM). This is a popular method of modern tunnel design and construction. When using this method, the entire profile of the tunnel tube is not excavated at once, the excavation takes place one section at a time. Thanks to this process, the bearing function of the rock 

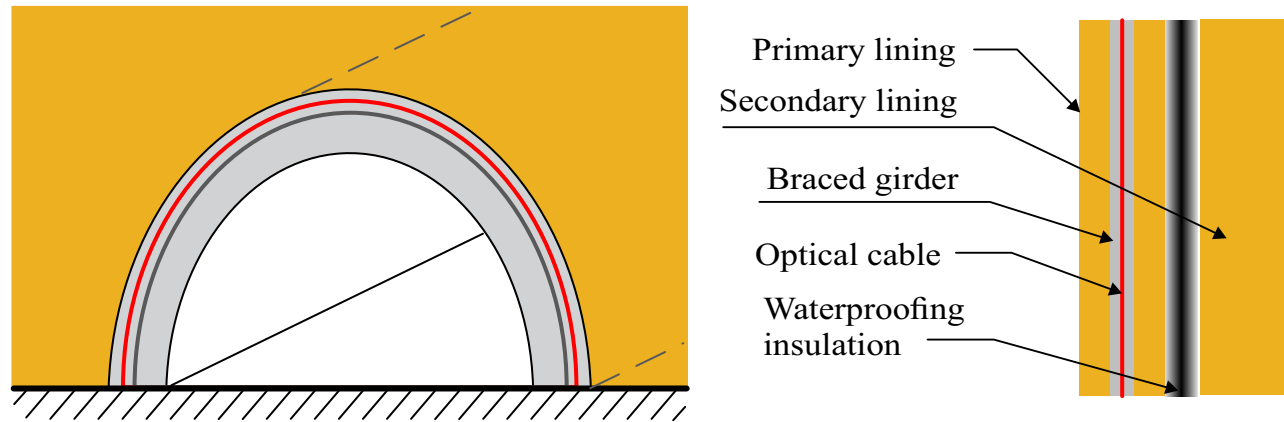

Fig. 2. The tunnel in Žilina: (a) - tunnel structure, (b) - detail of wall
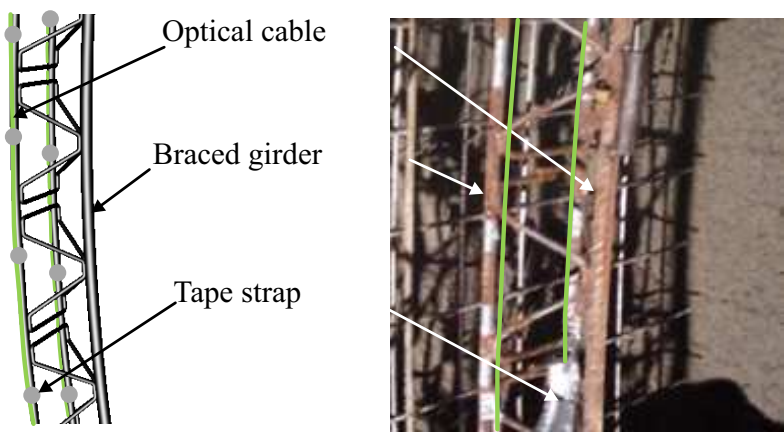

Fig. 3. Optical fiber implementation on iron bars of the braced girder of the primary lining: (a) - scheme of implementation, (b) practical implementation

mass can also be used. An integral part of the excavation process using the New Austrian Tunnelling Method is a geotechnical monitoring, which allows time optimization during the installation of the tunnel lining.

The tunnel lining consists of two parts, namely the primary and secondary lining, see Fig. 2(a), detail of wall, see Fig. 2(b). The primary lining is built right after the excavation works. A grating and a braced girder is installed in the intrados of the stope. This part is reinforced by sprayed concrete. The primary lining with a thickness of 200 to $400 \mathrm{~mm}$ provides temporary stability of the entire stope. The secondary lining, which is usually a ferro-concrete shell, rarely a shell from concrete itself and quite often with the use of the so-called tubbings (pre-fabricated components), is built as a final lining of the underground working Between the primary and the secondary lining, a waterproofing spacer is inserted, which protects the secondary lining from water activity for the whole life of the working.

\subsection{The optical fibre}

A special type of optical cable labelled as OFS Accudry Flex+ ZWP BIF G.657.A2 was used for the distributed measurement. The optical cable consists of a standard telecommunication single-mode optical fibre in a primary acrylate cover, a secondary cover of $900 \mu \mathrm{m}$, aramid yarn with an outer cover that is $3 \mathrm{~mm}$ thick. The cable was chosen for its properties that are suitable for installation or placing into concrete for the purpose of measuring the deformation affecting the given monitored area, and for its price, which is in the range of several euros (up to 10) per meter. The optical fibre was placed on two iron bars of the braced girder of the tunnel, which became a part of the primary lining after being sprayed with concrete. A model of the optical fibre implementation on the iron bars of the braced girder can be seen on Fig. 3(a), the practical implementation is shown in Fig. 3(b) (red indicates the placement of the cable). The optical cable was installed in place $\mathrm{A}$ and along the construction, and the iron bars of the iron support in place E and back, see Fig. 4. The cable was a twin cable which ensured the redundancy of the measurement (measurement channel 1 and measurement channel 2 .

The installation into the primary lining was performed on January 14, 2017, at a distance of $350 \mathrm{~m}$ from the entrance to the tunnel. The optical cable was taken out of the primary lining at an approximate height of $2 \mathrm{~m}$ and placed in a distribution box.

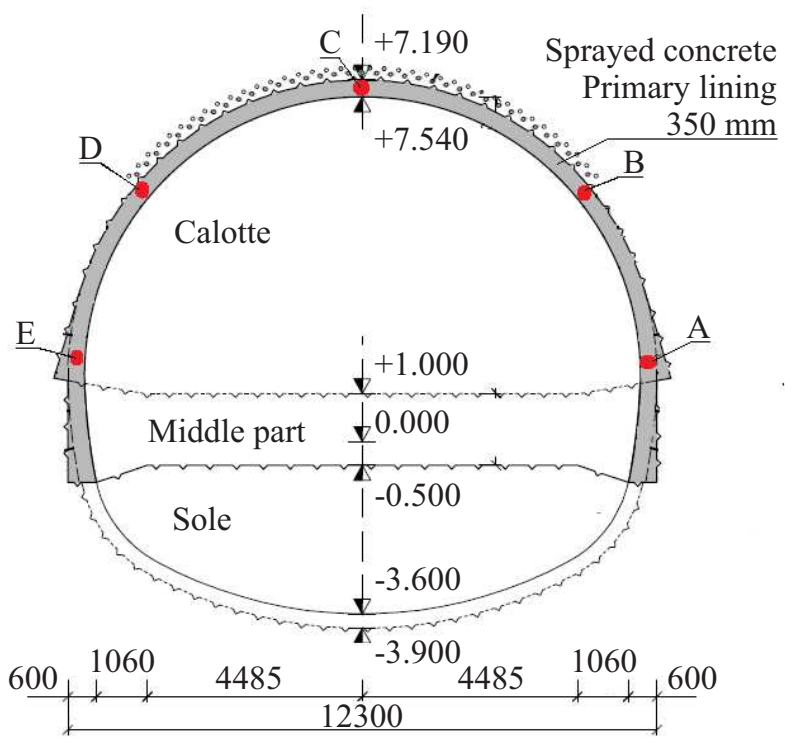

Fig. 4. Structure of tunnel with dimensions and marked points

Figure 4 shows the tunnel with highlighted horizontal and vertical dimensions. Grey indicates the primary lining for which the sprayed concrete was used. The thickness of the sprayed concrete is $350 \mathrm{~mm}$ and the optical 

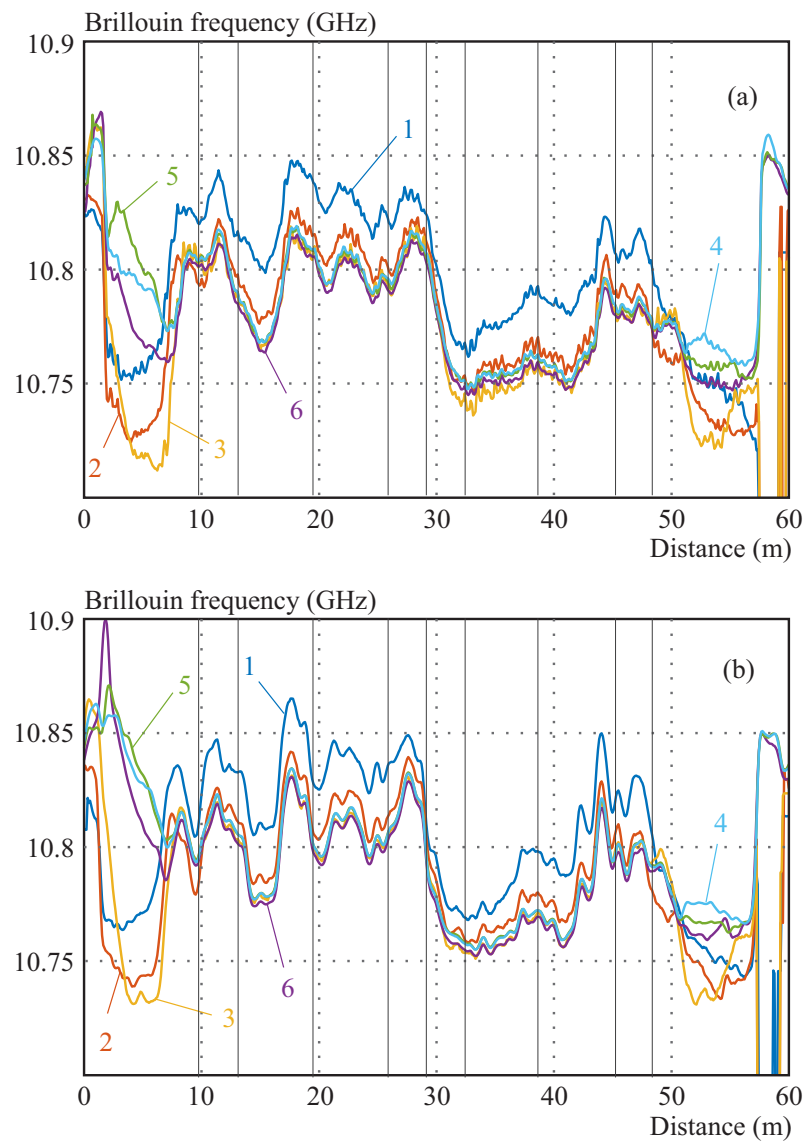

Fig. 5. Measurement of Brillouin frequency from 6 measurements over the five-month time horizon according to Tab. 2 (a) - first channel, and (b) - the second channel

cable for the measurement with DSTS system was implemented there. Red marks indicate the spots in the primary linings with marks A, B, C, D, E. The changes of the load in the experimental part will be compared in these spots.

Table 1. Length of optical cable in primary lining from entrance point A to other points

\begin{tabular}{lcc}
\hline Point & $\begin{array}{c}\text { Distance of } \\
\text { primary lining } \\
(\mathrm{m})\end{array}$ & $\begin{array}{c}\text { Distance of } \\
\text { optical cable } \\
(\mathrm{m})\end{array}$ \\
\hline A & 0.000 & 9.893 \\
B & 3.210 & 13.103 \\
C & 9.643 & 19.536 \\
D & 16,077 & 25.97 \\
E & 19.287 & 29.18 \\
D' $^{\prime}$ & 22.497 & 32.39 \\
C $^{\prime}$ & 28.930 & 38.823 \\
B $^{\prime}$ & 35.364 & 45.257 \\
A $^{\prime}$ & 38.574 & 48.467 \\
\hline
\end{tabular}

The curve of the primary lining (between place A and E) is $19.287 \mathrm{~m}$ long. Spot A stands for the place of the entrance of the optical cable into the primary lining. The optical cable is routed in the primary lining to spot E, where it is directed back to spot $\mathrm{A}$ and taken out of the primary lining. The distances from spot A to spots B, C, D, E and back in the direction of spots D', C', B' and A' are summarized in Tab. 1 in the 'Distance of primary lining $(\mathrm{m})$ ' column. The 'Distance of optical cable (m)' column defines the length of the optical cable to the given spots, because the lead-in cable from the measuring DSTS system to spot A was $9.893 \mathrm{~m}$. These distances should help give a clear overview of the measurements shown in the next chapter.

\section{Results}

The optical cable was implemented on January 14, 2017 in the braced girder using strapping tapes. The longtime measurement in the tunnel took place over 6 days during a period of 5 months, see Tab. 2. Each day for the measurement was chosen depending on the accessibility of the tunnel. On each day of the measurement, 25 measurements for each channel were performed and the results were averaged for subsequent processing. Consequently, the effect of the temperature in Brillouin frequencies was deducted based on the temperature measurement using referential temperature sensors that are installed in the primary lining along the measuring optical cable. The vertical lines in following figures represent selected points A, B, C, D, E, D', C', B', A', see Tab. 1. and the relevant days according to Tab. 2. are indicated by shown numbers(ID).

Table 2. Date of measurements

\begin{tabular}{cc}
\hline ID & \multicolumn{1}{c}{ Date } \\
\hline 1 & 19.1 .2017 \\
2 & 3.2 .2017 \\
3 & 22.3 .2017 \\
4 & 25.4 .2017 \\
5 & 7.6 .2017 \\
6 & 21.6 .2017 \\
\hline
\end{tabular}

Each averaged measurement from five days of the measurement is shown in Fig. 5(a) for the first channel and Fig. 5(b) for the second channel. The part of the route from $\mathrm{A}$ to $\mathrm{E}$ was intentionally more tensed during the implementation of the optical fibre than the return part of the route from $\mathrm{E}$ to $\mathrm{A}$ '. The idea behind this approach was to verify whether the tension of the optical fibre influences the sensitivity of the DSTS measurement system.

The figures show the absolute values of Brillouin frequency from the two channels of the optical cable in the primary lining of the tunnel. An increase in Brillouin frequency (the part of the route from A to E) is evident on both channels, and it is caused by the tension of the optical cable that was implemented on the braced girder. 

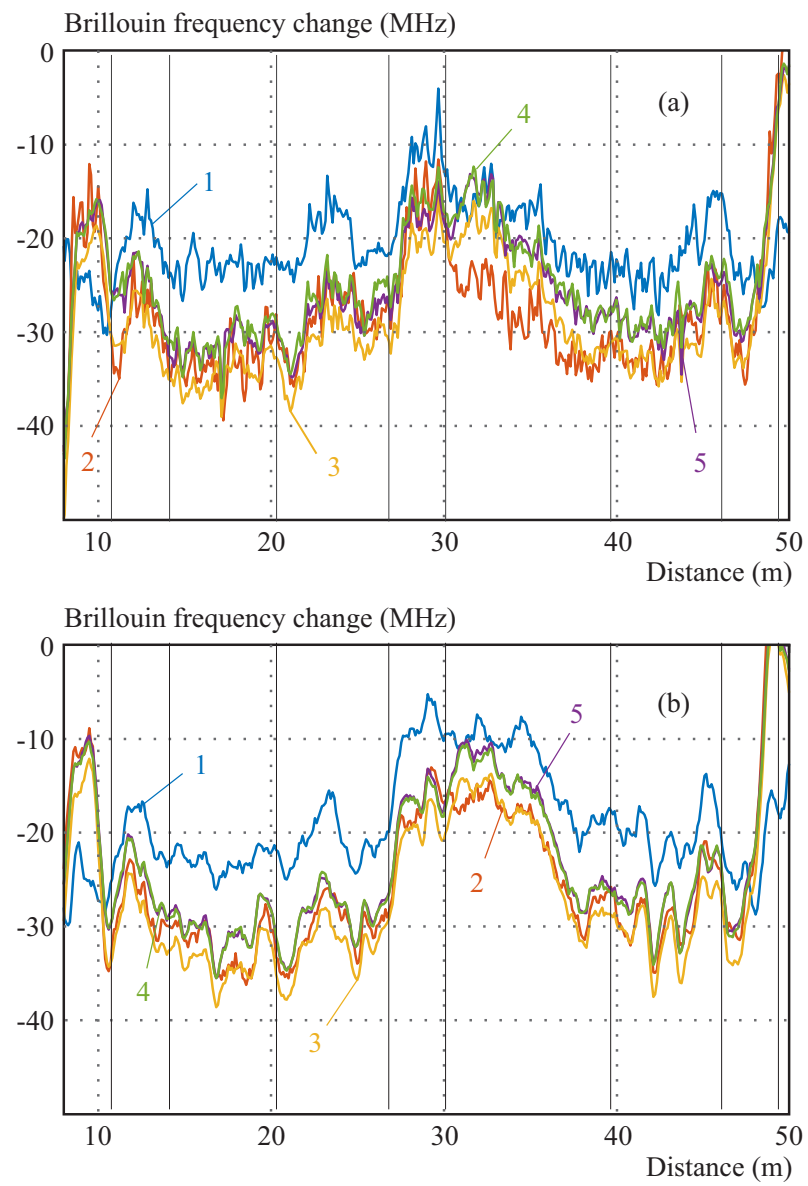

Fig. 6. Changes in Brillouin Frequency from 6 measurements according to Tab. 2 versus the first measurement of 19.1.2017 (a) first channel; and (b) - the second channel

The effect of the tension could be eliminated by performing a referential measurement of Brillouin frequency before the primary lining was sprayed; this would define how significant the effect of concrete setting in the primary lining is.

Due to time constraints (the progress of works during the excavation by Metrostav did not allow any time interval for referential measurement), the introductory referential measurement with DSTS before spraying the primary lining was not performed. Moreover, due to the unstable overburden of the tunnel, the main requirement of Metrostav was to determine the changes of load (the changes of Brillouin frequency) of the tunnel over time, whether there is an increase in pressure on the primary lining or the load of the primary lining is stable. Although the referential measurement did not take place, it is possible to track the required changes of Brillouin frequency in relation to the first day of the measurement. This monitoring has been in progress for six months, and it will continue until the end of 2017 , ie for the entire duration of the construction works. This article analyzes the data from the first six months of the measurements in 2017.

Regarding the load of the primary lining, information about changes in the load of the monitored part during the construction works is vital. Figure 6 shows the changes of Brillouin frequency. The individual curves
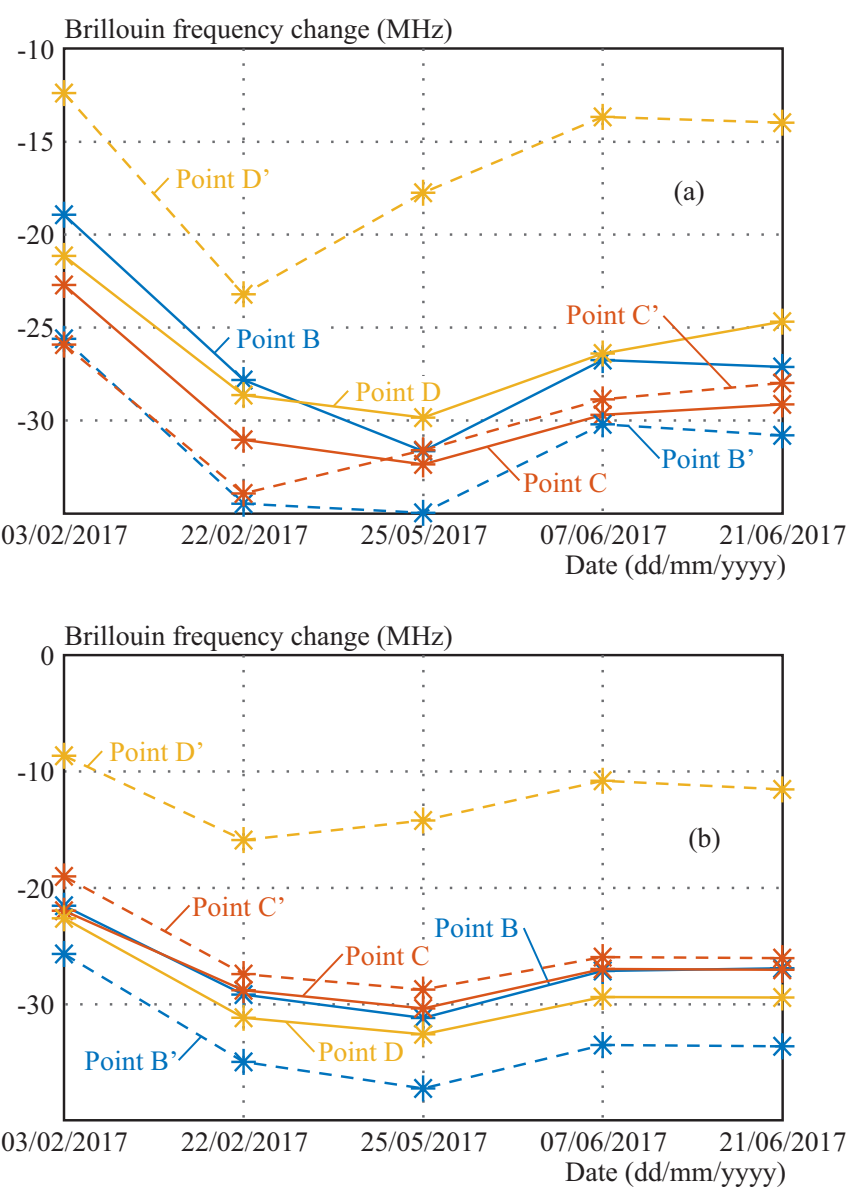

Fig. 7. Development of Brillouin frequency on individual measurement days at selected points: (a) - in the first channel, and (b) - the second channel

show the change of Brillouin frequency in relation to the first measurement that took place 4 days after the implementation of the optical cable into the primary lining.

Figure 7 shows the development of Brillouin frequency on individual days of the measurement. Figure 7(a) shows the development of Brillouin frequency regarding the first channel in the spots marked B, C, D, B', C' and D'. Figure $7(\mathrm{~b})$ shows the development of Brillouin frequency regarding the second channel in the spots marked $\mathrm{B}, \mathrm{C}$, D, B', C' and D'.

In the first measuring cycle on February 3, 2017, there is an obvious decrease of Brillouin frequency that is caused by the cooling of the concrete after an increased temperature caused by the hydration of the concrete ($20 \mathrm{MHz}$ ). The following decrease may be due to the combination of the temperature drop to the level of the surrounding rock mass temperature, and by the shrinkage of concrete. Subsequently, the initial distorting effects are stabilized. The last two measurements do not show any significant changes that can tell us the surrounding rock was relatively at rest, but we need to take into consideration the fact that the movement of rock mass is a longterm matter. The following measurements will monitor other possible changes in the load of the primary lining. 


\section{Conclusion}

This article describes the use of the Distributed Fiber Optical System (DSTS) based on the Brillouin Time Domain Reflectometry (BOTDR) for the analysis and safety monitoring of the structural loads of road and motorway tunnels. The measurement principle is based on the measurement and analysis of stimulated Brillouin scattering. The article describes the long-term real experimental measurement of tunnel load which was carried out during the construction of a motorway tunnel in Slovakia. The measurement was carried out over a period of several months. The experimental measurements were carried out with a standard optical telecommunication cable with water-absorbing aramid yarns and a jacket with a $4.2 \mathrm{~mm}$ diameter.

\section{Acknowledgements}

This article was supported by the Ministry of Education of the Czech Republic (projects SP2017/128 and SP2017/79). This research was partially supported by the Ministry of Education, Youth and Sports of the Czech Republic through grant project CZ.1.07/2.3.00/20.0217 within the framework of the operation programme Education for competitiveness financed by the European structural funds and from the state budget of the Czech Republic. The paper was prepared with the support of the Competence Centers of the Technology Agency of the Czech Republic (TACR) within the project Center for Effective and sustainable transport infrastructure (CESTI), project number TE01020168

\section{REFERENCES}

[1] P. Lunardi, Design and Construction of Tunnels, 1st ed. Berlin Heidelberg: Springer-Verlag Berlin Heidelberg, 2008.

[2] L. Uotinen, "Design of Shotcrete Rock Reinforcement Hard Rock according to Eurocode", Seminar on Geoengineering, Espoo, Finland, 2011.

[3] G. C. Cho, J. H. Lee, K. I. Song and S. R. Lee, Proceedings of the World Tunnel Congress, 2007.

[4] J. Singer, H. Grafinger and K. Thuro, "Monitoring the Deformation of a Temporary Top Heading Invert using Time Domain Reflectometry", Geomech. und Tunnelbau, vol. 2, no. 3, pp. 238-249, 2009.

[5] R. Farrell, R. Mair, A. Sciotti and A. Pigorini, "Building Response to Tunnelling", Soils Found., vol. 54, no. 3, pp. 269-279, 2014.

[6] Z. Sikora and R.Ossowski, "Geotechnical Aspects of Dike Construction using Soil-Ash Composites", Procedia Engineering, 2013, vol. 57, pp. 1029-1035.

[7] E. Hrubesova, L. Duris, A. Melichar and M. Jaafar, "Determination of Tunnel Face Stabilizing Pressure using Numerical and Analytical Methods", Advances and Trends Engineering Sciences and Technologies II - Proceedings of the 2nd International Conference on Engineering Sciences and Technologies, ESaT 2016, 2017, pp. 767-772.

[8] E. Hrubesova, H. Lahuta, L. Duris and M. Jaafar, "Mathematical Modeling of Foundation-Subsoil Interaction", International Multidisciplinary Scientific GeoConference Surveying Geology and Mining Ecology Management, SGEM, 2015, vol. 2, no. 1, pp. $437-444$.
[9] S. Argyroudis, A. M. Kaynia and K. Pitilakis, "Development of Fragility Functions for Geotechnical Constructions: Application to Cantilever Retaining Walls", Soil Dyn. Earthq. Eng., vol. 50, pp. 106-116, 2013.

[10] A. F. Cabalar, A. Cevik and C. Gokceoglu, "Some Applications of Adaptive Neuro-Fuzzy Inference System (ANFIS) Geotechnical Engineering", Comput. Geotech., vol. 40, pp. 14-33, 2012.

11] C. Kolat, R. Ulusay and M. L. Suzen, "Development of Geotechnical Microzonation Model for Yenisehir (Bursa, Turkey) Located at a Seismically Active Region", Eng. Geol., vol. 127, pp. 36-53, 2012.

[12] H. S. Kim, G. C. Cho, J. Y. Lee, and S. J. Kim, "Geotechnical and Geophysical Properties of Deep Marine Fine-Grained Sediments Recovered during the Second Ulleung Basin Gas Hydrate Expedition, East Sea, Korea", Mar. Pet. Geol., vol. 47, pp. 56-65, 2013.

13] F. Shaaban, A. Ismail, U. Massoud, H. Mesbah, A. Lethy and A. M. Abbas, "Geotechnical Assessment of Ground Conditions Around a Tilted Building Cairo, Egypt using Geophysical Approaches", Arab. J. Geosci., vol. 6, no. 12, pp. 4961-4972, 2013.

[14] S. Jia, Y. Zhao and C. Zou, "Numerical Solution to Identification Problems of Material Parameters Geotechnical Engineering", Procedia Engineering, 2012, vol. 28, pp. 61-65.

15] I. Papaioannou and D. Straub, "Reliability Updating Geotechnical Engineering Including Spatial Variability of Soil", Comput. Geotech., vol. 42, pp. 44-51, 2012

[16] M. Ghorbani, M. Sharifzadeh, S. Yasrobi and D. M. aiyan, "Geotechnical, Structural and Geodetic Measurements for Conventional Tunnelling Hazards Urban Areas - the Case of Niayesh Road Tunnel Project", Tunn. Undergr. Sp. Technol., vol. 31, pp. 1-8, 2012.

17] M. Al-Mukhtar, S. Khattab and J.-F. Alcover, "Microstructure and Geotechnical Properties of Lime-Treated Expansive Clayey Soil", Eng. Geol., vol. 139-140, pp. 17-27, 2012.

[18] G. Song, W. Li, B. Wang and S. C. M. Ho, "A Review of Rock Bolt Monitoring using Smart Sensors", vol. 17, no. 4.MDPI AG, 05-Apr-2017.

[19] S. C. M. Ho, W. Li, B. Wang and G. Song, "A Load Measuring Anchor Plate for Rock Bolt using Fiber Optic Sensor", vol. 26, no. 5, April 2017.

[20] T. M. Do and Y. S. Kim, "Prediction of Load Transfer Depth for Cost-Effective Design of Ground Anchors using FBG Sensors Embedded Tendon and Numerical Analysis", vol. 10, no. 6, pp. 737-755, June 2016.

[21] W. Moorman, L. Taerwe, W. De Waele, J. Degrieck, and J. Himpe, "Measuring Ground Anchor Forces of a Quay Wall with Bragg Sensors", vol. 131, no. 2, pp. 322-328, February 2005.

[22] M. Schroeck, W. Ecke, and A. Graupner, "Strain Monitoring Steel Rock Bolts using FBG Sensor Arrays", vol. 4074, pp. 298-304, 2000.

[23] X. Weng, H. Ma, and J. Wang, "Stress Monitoring for Anchor Rods System Subway Tunnel using FBG Technology", vol. 2015, 1.2.2015.

[24] S. Li, J. Ma, and J. Hu, "Rockfall hazard alarm strategy based on FBG smart passive net structure", vol. 5, no. 1, pp. 19-23, Mar 2015.

[25] Q. Jiang, Q. M. Sui, Q. S. Zhang, and X. Z. Cui, "Technology Study of Optical Fiber Bragg Grating Anchor Bar Sensor Tunnel Strain Monitoring", vol. 27, SUPPL., pp. 315-318, Oct 2006.

[26] Y. Guan et al "Monitoring Research of Fiber Bragg Grating Strain Sensors Embedded Tunnel Secondary Lining", Guangxue Jishu/Optical Tech., vol. 40, no. 6, pp. 547-550, 2014.

[27] T. Nishino, "Measurement of Tunnel-Ceiling and Side-Wall Displacements using Arc-Shaped Beam and Fiber Bragg Grating Sensors Hiroshi Naruse, Shinya Furukaw1", 2012, vol. 8421.

[28] M. Fajkus et al "Mathematical Model of Optimized Design of Multi-Point Sensoric Measurement with Bragg Gratings using 
Wavelength Divison Multiplex", Proceedings of SPIE - The International Society for Optical Engineering, 2016, vol. 9889.

[29] M. Fajkus et al "Capacity of Wavelength and Time Division Multiplexing for Quasi-Distributed Measurement using Fiber Bragg Gratings", Adv. Electr. Electron. Eng., vol. 13, no. 5, 2015.

[30] M. Papes et al "Concrete Deflection Measurement using Fiber Optic Distributed Strain System", Proceedings of SPIE - The International Society for Optical Engineering, 2015, vol. 9659.

[31] M. Fajkus et al "Effect of the Geometric Deformations on the Brillouin Scattering the Standard Single-Mode Optical Fiber", Proceedings of SPIE - The International Society for Optical Engineering, 2016, vol. 9889.

[32] M. Fajkus, J. Nedoma, L. Bednarek, J. Frnda and V. Vasinek, "Analysis of the Applicability of Singlemode Optical Fibers for Measurement of Deformation with Distributed Systems BOTDR" Adv. Electr. Electron. Eng., vol. 14, no. 4Special, 2016.

[33] F. Wang, H. Huang, D. Zhang, W. Zhang and R. Xu, "Deformation Sensing Mehod of Shield Tunnel based on Optical Fiber Sensing Technology of BOTDA", vol. 32, no. 9, pp. 1901-1908, Sep 2013.

[34] S. Song, Z. Wu, C. Yang, C. Wan and S. Shen, "Deformation Monitoring of Shield Tunnel based on Distributed Optical Fiber Strain Sensing Technology", 2011, vol. 2, pp. 2058-2066.

[35] H. T. Qiu, C. Li, H. L. Cui, D. Zhang and Y. Ding, "Stain Monitoring for Tunnel using Distributed Optical Fiber BOTDR Sensors", 2008, pp. 27-30.

[36] R. A. Moffat, J. F. Beltran and R. Herrera "Applications of BOTDR Fiber Optics to the Monitoring of Underground Structures", vol. 9, no. 3, pp. 397-414, Sep 2015.

[37] B. Shi et al "Study on BOTDR-based Distributed Optical Fiber Strain Measurement for Tunnel Health Diagnosis", vol. 24, no. 15, pp. 2622-2628, Aug 2005.

[38] J. Ching and K.-K. Phoon, "Quantile Value Method versus Design Value Method for Calibration of Reliability-Based Geotechnical Codes", Struct. Saf., vol. 44, pp. 47-58, 2013.

[39] M. Ghayoomi, S. Dashti and J. S. McCartney, "Performance of a Transparent Flexible Shear Beam Container for Geotechnical Centrifuge Modeling of Dynamic Problems", Soil Dyn. Earthq. Eng., vol. 53, pp. 230-239, 2013.

[40] C. H. Juang and L. Wang, "Reliability-Based Robust Geotechnical Design of Spread Foundations using Multi-Objective Genetic Algorithm", Comput. Geotech., vol. 48, pp. 96-106, 2013.

[41] T. Horiguchi, K. Shimizu, T. Kurashima, M. Tateda and Y. Koyamada, "Development of a Distributed Sensing Technique using Brillouin Scattering", Journal of Lightwave Technology, vol. 13, no. 7, pp. 1296-1302, July 1995.

[42] Z. Xiaofei, H. Wenjie, Z. Qing, S. Yanxin, M. Xianwei and H. Yongwen, "Development of Optical Fiber Strain Monitoring System based on BOTDR", IEEE 2011 10th International Conference on Electronic Measurement Instruments, 2011, vol. 4, pp. $38-41$.

Received 9 July 2017

Marcel Fajkus was born in 1987 in Ostrava. In 2009 he received a Bachelor degree from VSB-Technical University of Ostrava, Faculty of Electrical Engineering and Computer Science, Department of Telecommunications and later the Master degree in the field of telecommunications. He is currently PhD student of Department of Telecommunications at VSBTechnical University in Ostrava. He works in the field of optical communications and fiber optic sensor systems and published more than 80 journal and conference articles.
Jan Nedoma was born in 1988 in Prostějov. In 2012 he received a Bachelor degree from VSB-Technical University of Ostrava, Faculty of Electrical Engineering and Computer Science, Department of Telecommunications and later the Master degree in the field of Telecommunications. He is currently PhD student of Department of Telecommunications at VSBTechnical University of Ostrava. He works in the field of optical communications and fiber optic sensor systems. He has more than 75 journal and conference articles.

Pavel Mec was born in 1985 in Ostrava. He graduated from Civil engineering at secondary school. After that he continued the study of civil engineering at VSBTU Ostrava with field of study Building materials and diagnostic of building and also Building structures. For three years he also studied the computational mathematics. He specializes in material research, both in terms of material engineering and mechanics.

Eva Hrubešová was born Ostrava. In 1985 she graduated from the Faculty of Natural Science of Palacky University in Olomouc in the field Mathematical analysis. In 1999 she obtained $\mathrm{PhD}$ degree in the field of Rock Engineering at VSB-Technical university in Ostrava and in 2006 she was appointed Associate Professor for Geotechnics and Underground Engineering at this university. Since 2007 she is Head of the Department of Geotechnics and Underground Engineering at the Faculty of Civil Engineering, VSB-TU Ostrava. She works in the field of mathematical modelling, mechanics of underground structures and geotechnical monitoring.

Radek Matínek was born in 1984 in Czech Republic. In 2009 he received Master degree in Information and Communication Technology from VSBTechnical University of Ostrava. Since 2012 he worked here as a Research Fellow. In 2014 he defended his dissertation thesis titled "The Use of Complex Adaptive Methods of Signal Processing for Refining the Diagnostic Quality of the Abdominal Fetal Electrocardiogram". In 2017 he became Associate Professor in Technical Cybernetics. His current research interests include: Digital Signal Processing (Linear and Adaptive Filtering, Soft Computing - Artificial Intelligence and Adaptive Fuzzy Systems, Non-Adaptive Methods, Biological Signal Processing, Digital Processing of Speech Signals); Wireless Communications (Software-Defined Radio); Power Quality Improvement. He has more than 100 journal and conference articles in his research area.

Vladimír Vašinek was born in Ostrava. In 1980 he graduated in Physics, specialization in Optoelectronics, from the Science Faculty of Palacky University. He gained the RNDr title from the Science Faculty of Palacky University in the field of Applied Electronics. The PhD was conferred upon him in the branch of Quantum Electronics and Optics in 1989. He became an associate professor in 1994 in the branch of Applied Physics and has been a professor of Electronics and Communication Science since 2007. He pursues this branch at the Department of Telecommunications at VSB-Technical University of Ostrava. His research work is dedicated to optical communications, optical fibers, optoelectronics, optical measurements, optical networks projecting, fiber optic sensors, MW access networks. He is a member of many societies - OSA, SPIE, EOS, Czech Photonics Society; he is a chairman of the PhD board at the VSB-Technical University of Ostrava and a member of habitation and professorship boards. 